\title{
Influence of depression symptoms on patient expectations and clinical outcomes in the surgical management of spinal stenosis
}

\author{
Alejandro Urban-Baeza, MD,, Barón Zárate-Kalfópulos, MD, ${ }^{1}$ Samuel Romero-Vargas, MD, ${ }^{1}$ \\ Claudia Obil-Chavarría, MD, ${ }^{1}$ Luis Brenes-Rojas, MD, ${ }^{1}$ and Alejandro Reyes-Sánchez, MD, PhD ${ }^{2}$ \\ ${ }^{1}$ Spine Surgery Service and ${ }^{2}$ Head Special Surgery Division, Instituto Nacional de Rehabilitación, Tlalpan, México
}

OBJECT This prospective cohort study was designed to determine the influence of depressive symptoms on patient expectations and the clinical outcomes of the surgical management of lumbar spinal stenosis.

METHODS Patients with an age > 45 years, a diagnosis of lumbar spinal stenosis at one level, and an indication for decompressive surgery were included in this study. Data for all of the following parameters were recorded: age, sex, highest level of education, and employment status. Depression symptoms (Beck Depression Inventory), disability (Oswestry Disability Index), and back and leg pain (visual analog scale) were assessed before surgery and at 12 months thereafter. The reasons for surgery and patient expectations (North American Spine Society lumbar spine questionnaire) were noted before surgery. The global effectiveness of surgery (Likert scale) was assessed at the 1-year follow-up.

RESULTS Fifty-eight patients were divided into two groups based on the presence (Group 1) or absence (Group 2) of depressive symptoms preoperatively; each group comprised 29 patients. Demographic data were similar in both groups before surgery. The main reason to undergo surgery was "fear of a worse situation" in 34\% of the patients in Group 1 and "to reduce pain" in $24 \%$ of the patients in Group 2. The most prevalent expectation was to improve my social life and my mental health in both groups. Surgery had a relieving effect on the depressive symptoms in 14 patients (48\%). Thus, in the postoperative period, the number of patients who were free of depressive symptoms was 43 compared with the 15 who were depressed $(p=0.001)$. The 15 patients with persistent depression symptoms after surgery had a worse clinical outcome compared with the 43 patients free of depression symptoms at the 1-year follow-up in terms of severe back pain ( $20 \%$ vs $0 \%$, respectively), severe leg pain ( $40 \%$ vs $2.3 \%$, respectively), and severe disability ( $53 \%$ vs $9.3 \%$, respectively). Only $33 \%$ of patients with persistent depression symptoms after surgery chose the option "surgery helped a lot" compared with $76 \%$ of patients without depression symptoms. Moreover, in terms of expectations regarding improvement in back pain, leg pain, walking capacity, independence, physical duties, and social activities, fewer patients were "completely satisfied" in the group with persistent depression symptoms after surgery.

CONCLUSIONS Surgery for spinal stenosis had a relieving effect on preoperative depression symptoms at the 1-year follow-up. The persistence of depressive symptoms after surgery correlated with a worse clinical outcome and a higher rate of unmet expectations. Screening measures to detect and treat depression symptoms in the perioperative period could lead to better clinical results and increased patient satisfaction.

http://thejns.org/doi/abs/10.3171/2014.10.SPINE131106

KEY WORDS lumbar spinal stenosis; patient expectations; depression symptoms; surgical treatment; decompression surgery; patient satisfaction; lumbar pain; surgery

$\mathrm{S}$ URGERY for lumbar spinal stenosis is an option for patients who remain severely symptomatic after a course of conservative treatment. Individual patient characteristics are related to the surgical outcomes for spinal stenosis. ${ }^{8,13}$ Patient expectations have been studied for lumbar stenosis..$^{9,10,21}$ Lutz et al. reported that patients with better expectations from their surgery had better outcomes after discectomy for disc herniation. ${ }^{11}$ In contrast, McGregor and colleagues reported that patients undergoing spinal stenosis surgery frequently had unrealistically high expectations from their surgery and tended to have lower levels of satisfaction; ${ }^{14,15}$ similarly, Toyone et al. reported that patients with spinal stenosis tend to have more unrealistic and, consequently, unfulfilled expectations. ${ }^{24}$

ABBREVIATIONS BDI = Beck Depression Inventory; NASS = North American Spine Society; ODI = Oswestry Disability Index; VAS = visual analog scale SUBMITTED December 5, 2013. ACCEPTED October 6, 2014.

INCLUDE WHEN CITING Published online November 7, 2014; DOI: 10.3171/2014.10.SPINE131106.

DISCLOSURE The authors report no conflict of interest concerning the materials or methods used in this study or the findings specified in this paper. 
Depression and painful conditions frequently coexist, and previous studies have demonstrated that depressive symptoms are associated with poorer outcomes following the surgical treatment of patients with lumbar stenosis. ${ }^{1,2,16-20,23,25}$ To our knowledge, there is no information in the literature concerning the influence of depression symptoms on patient expectations. We hypothesized that patient expectations can be affected by depression symptoms and, consequently, will affect clinical results. In this prospective cohort study, we explored the role of depression symptoms in patient expectations and the clinical results of surgery for degenerative lumbar spinal disorders.

\section{Methods}

All of the patients received both an oral and a written explanation of what would be required of them, and they signed an informed consent form confirming their agreement to participate in the present study. The local ethics committee of the Instituto Nacional de Rehabilitación approved this study. The study inclusion criteria were as follows: age over 45 years, diagnosis of lumbar spinal stenosis at one level between March 2011 and March 2012 with an indication for decompression surgery with or without fusion, failed conservative therapy, and willingness to comply with the predetermined follow-ups.

Data regarding patient age, sex, highest education level, and work status were obtained for all of the patients. Patient expectations (North American Spine Society lumbar spine questionnaire) and reasons for surgery were noted before the surgery. Disability (Oswestry Disability Index [ODI]), depression (Beck Depression Inventory [BDI]), and back and leg pain (visual analog scale) questionnaires were completed by the patient at the hospital 1 week before surgery and by physician interview at 12 months after surgery. An orthopedic surgeon who was not directly related to the surgical treatment or to the spine surgeon follow-up conducted the interview. The global effectiveness of surgery (Likert scale) was assessed at the 1-year follow-up.

\section{Reasons for Surgery}

The patients were asked to provide their 3 most important reasons for deciding to undergo surgery, selected from the following list: other therapies had not helped, fear of a worsening of their situation, desire to retain their independence, desire to improve their performance of everyday activities, desire to improve their walking capacity, desire to reduce pain, or their physician had recommended the surgery.

\section{Patient Expectations}

Patient expectations were assessed using a modified version of the Expectations Scale of the North American Spine Society (NASS) lumbar spine questionnaire. ${ }^{5}$ The question, "What changes in the following items do you expect to experience as a result of the operation?" was asked regarding each of the following 8 items: leg pain, back pain, walking capacity, independence in everyday activities, general physical capacity (at home and work), ability to participate in sports, frequency and quality of social contacts, and mental well being. The response options were as follows: much better, better, somewhat better, unchanged, and worse; "I don't know" was also an option.

\section{Global Effectiveness of Surgery}

At the follow-up, the patients rated the global effectiveness of the surgery on a 5-point Likert scale (that is, surgery helped a lot, helped, helped only a little, did not help, or made things worse).

\section{Depression Symptoms}

Depressive symptoms were assessed using the Spanish version of the 21-item Beck Depression Inventory (BDI), with scores ranging from 0 to $36 .{ }^{4} \mathrm{~A}$ score of $0-9$ indicated a normal mood, and 10 or more indicated depression, that is, elevated depressive symptoms. A score of 10-29 indicated mild to moderate depression symptoms, and a score of 30-36 indicated severe depression symptoms.

\section{Pain and Disability}

Back and leg pain intensities were assessed using a visual analog scale (VAS; range $0-10 \mathrm{~cm}) .{ }^{6}$ Patients were divided into 3 subgroups according to the intensity of their leg or back pain, as determined by the VAS: 1-3, mild; 4-7, moderate; and 8-10, severe.

Subjective disability was measured using the validated Finnish version of the Oswestry Disability Index (ODI; $0 \%-100 \%$ ) in which $21 \%-40 \%$ is considered moderate disability, $41 \%-60 \%$ is considered severe disability, $61 \%-$ $80 \%$ is considered crippled, and $81 \%-100 \%$ is considered patient exaggeration of their symptoms. ${ }^{22}$

\section{Statistical Analysis}

The sample of subjects was dichotomized according to the presence or absence of depressive symptoms (at least one positive answer on the Spanish version of the BDI II).

All of the baseline measures were obtained 1 week before surgery, and follow-up assessments were conducted 12 months after surgery (VAS, ODI, and BDI).

Categorical values were compared using a chi-square test. The Student t-test was used to compare the postoperative symptom scores (lumbar VAS, leg VAS, and ODI) between groups.

Statistical significance was accepted at a p value $<0.05$. Statistical analyses were performed using SPSS version 11.0 for Mac.

\section{Results}

Fifty-eight patients were included in this analysis: 30 males (51.72\%) and 28 females (48.27\%). Of these 58 patients, 29 (50\%) had no depressive symptoms, 22 (37.93\%) had mild depressive symptoms, $6(10.34 \%)$ had moderate depressive symptoms, and $1(1.72 \%)$ had severe depressive symptoms, according to the BDI. Patients were divided into two groups based on the presence (Group 1) or absence (Group 2) of depressive symptoms preoperatively. Group 1 comprised 16 females and 13 males, whereas Group 2 consisted of 14 females and 15 males. Demographic data were similar in both groups. The median age 
at surgery was $56 \pm 11$ years. Preoperative employment status in Group 1 was as follows: $58.62 \%$ (17 patients) were inactive (that is, retired or unemployed), and $41.37 \%$ were working (12 patients). In Group 2, 65.51\% (19 patients) were inactive and $34.48 \%$ (10 patients) were employed. Perioperative data were also similar between the groups in terms of the average surgical time, blood loss, and hospital stay. Regarding perioperative complications, 8 (13.79\%) dural sac tears occurred: 3 in Group 1 and 5 in Group 2. None of the patients needed revision surgery during the 1-year follow-up (Table 1).

Preoperatively, severe back pain was present in $48 \%$ and severe leg pain in $72 \%$ of patients in Group 1 (more than 7 points on the VAS), rates similar to those in Group 2 (51\% and $62 \%$, respectively). Regarding disability measured using the ODI, $48 \%$ of patients with depression symptoms had severe disability compared with $58 \%$ of patients without depression symptoms. No statistically significant difference in preoperative lumbar pain $(\mathrm{p}=0.39)$, leg pain $(\mathrm{p}=0.78)$, and disability $(\mathrm{p}=0.58)$ was found between the groups.

The reasons to undergo decompressive surgery were similar between the groups. The reason most frequently cited for undergoing surgery was to reduce pain (24\%) according to the group without depression symptoms (Group 2) and "fear of a worse situation" (34\%) according to the patients with depressive symptoms (Group 1).

Preoperative expectations between the patient groups were very similar, and the most prevalent expectations for surgery in both groups were to improve social life and mental health. Using the BDI, we found that surgery had a relieving effect on the depressive symptoms; among 29 patients with depressive symptoms in the preoperative period (score $>10$ points on the BDI), only 15 retained the depressive symptoms after surgery. The latter finding indicates that during the postoperative period, 43 patients were free of depressive symptoms and 15 patients were depressed $(p=0.001)$.

We performed a subanalysis comparing the 15 patients who remained depressed (persistent depression symptoms after surgery) and the 43 patients free of depressive symptoms during the postoperative period. We found statisti-

TABLE 1. Comparative demographic data in patients with (Group 1) and without (Group 2) depressive symptoms

\begin{tabular}{lcc}
\hline \multicolumn{1}{c}{ Factor } & Group 1 & Group 2 \\
\hline Total no. of patients & 29 & 29 \\
\hline Sex (M/F) & $13: 16$ & $15: 14$ \\
\hline Median \pm SD age at surgery in yrs & $57 \pm 11$ & $56 \pm 10$ \\
\hline Preop employment status & & \\
\hline \multicolumn{1}{c}{ Employed } & $41.37 \%$ & $34.48 \%$ \\
\hline$\quad$ Unemployed & $58.6 \%$ & $65.51 \%$ \\
\hline Mean \pm SD body mass index in $\mathrm{kg} / \mathrm{m}^{2}$ & $27 \pm 4$ & $28 \pm 6$ \\
\hline Regular exercise activity & $10.34 \%$ & $7.22 \%$ \\
\hline Average surgical time in minutes & 191 & 183 \\
\hline Average blood loss in $\mathrm{ml}$ & 280 & 300 \\
\hline Average hospital stay in days & 2.5 & 2.7 \\
\hline Dural sac tear & 3 & 5 \\
\hline
\end{tabular}

cally significant differences in lumbar pain $(\mathrm{p}=0.00)$, leg pain $(\mathrm{p}=0.05)$, and disability outcome $(\mathrm{p}=0.00)$, with consistently worse outcomes in patients with persistent depressive symptoms after surgery (Table 2 ).

In terms of the global effectiveness of surgery, $33 \%$ of patients with persistent depression after surgery chose the option "surgery helped a lot" versus $76 \%$ of patients without depression symptoms after surgery $(\mathrm{p}=0.001)$.

When patients were asked about expectations of improvement in back pain, leg pain, walking capacity, independence, physical duties, and social activities, the percentage of patients who chose the option "much better" was lower in the group with persistent depression symptoms after surgery than in patients without depression symptoms (back pain: $81 \%$ vs $60 \%$, respectively, $\mathrm{p}=001$; leg pain: $81 \%$ vs $46 \%$, respectively, $p=0.10$; walking capacity: $79 \%$ vs $40 \%$, respectively, $\mathrm{p}=001$; independence: $58 \%$ vs $13 \%$, respectively, $\mathrm{p}=001$; physical duties: $58 \%$ vs $26 \%$, respectively, $\mathrm{p}=0.05$; social activities: $79 \%$ vs $44 \%$, respectively, $\mathrm{p}=0.001$ ).

\section{Discussion}

In the present 12-month longitudinal cohort study, we aimed to assess the role of preoperative depression symptoms on the expectations for and the clinical results of the surgical treatment of lumbar spinal stenosis. Of our 58 patients, 29 (50\%) had preoperative depression symptoms. This rate is higher than the $20 \%$ reported by Sinikallio and colleagues. ${ }^{17-19}$

The first important finding of our study was that surgery had a relieving effect on depressive symptoms: among 29 patients with depressive symptoms in the preoperative period, only 15 retained these symptoms after surgery. This finding indicates that during the postoperative period, 43 patients were free of depressive symptoms, and 15 patients were depressed $(p=0.00)$. Similarly, Sinikallio et al. ${ }^{19} \mathrm{de}-$ scribed 45 patients with preoperative depression among a cohort of 96; 22 patients had recovered from depression symptoms at the 2-year follow-up. Note that the patients with persistent depression after surgery had shown worse improvement in symptom severity, disability scores, and walking capacity than the patients who had no depression at any stage. In those who had recovered from depression, the postoperative improvement was similar to that in the normal mood group. Those findings correlate with results in our study, in which persistent depression at the 1-year

TABLE 2. Comparison of patients with (Group 1) and without (Group 2) persistent depression symptoms after surgery

\begin{tabular}{llc}
\hline \multirow{2}{*}{ Factor } & \multicolumn{2}{c}{ No. (\%) } \\
\cline { 2 - 3 } & Group 1 & Group 2 \\
\hline No. of patients & 15 & 43 \\
\hline Free of back pain (VAS 0) & $9(60)$ & $20(46)$ \\
\hline Free of leg pain (VAS 0) & $2(13.3)$ & $17(40)$ \\
\hline Moderate disability (ODI 21\%-40\%) & $7(47)$ & $24(56)$ \\
\hline Severe back pain (VAS 8-10) & $3(20)$ & $0(0)$ \\
\hline Severe leg pain (VAS 8-10) & $6(40)$ & $1(2.3)$ \\
\hline Severe disability (ODI 61\%-80\%) & $8(53)$ & $4(9.3)$ \\
\hline
\end{tabular}


follow-up was associated with poorer outcomes in terms of lumbar pain $(p=0.00)$, leg pain $(p=0.05)$, and disability $(p=0.00)$. Notably, this clinical difference was present only in patients with persistent depression after surgery. In the original groups, we found differences only in leg pain: outcomes were worse in the depressive symptoms group $(\mathrm{p}=0.05)$, but the lumbar pain and disability outcomes were similar between the groups. These findings correlate with those of Sinikallio et al. in 2011; that is, patients with continuous depression after surgery showed poorer improvement in symptom severity, disability scores, and walking capacity, whereas patients who recovered from depression showed clinical improvement similar to that in the normal mood group. ${ }^{19}$

In another study of 232 patients who had undergone instrumented lumbar spine fusion, the authors noted that $32 \%$ of patients had preoperative depression symptoms but only $15 \%$ had them at the 1-year follow-up. ${ }^{25}$ These researchers concluded that the prevalence of depressive symptoms decreased after surgery. Disability remained higher in patients who had reported depressive symptoms preoperatively but decreased significantly after surgery; thus, the authors suggested that there was no need to exclude depressive patients from surgery, although screening measures and appropriate treatment practices were encouraged.

The reasons for undergoing decompressive surgery were similar between the groups in our analysis, except for the "fear of a worse situation," which was more frequently associated with the patients with depressive symptoms. In the group without depressive symptoms, a desire to improve pain was the most frequent reason for undergoing surgery. These results differ from those of Toyone et al. ${ }^{24}$ in 2005, in which reducing leg pain was the main reason to undergo surgery among patients with lumbar spinal stenosis and disc herniation.

Patient expectations were very similar between our groups, with the most prevalent being the improvement of social life and mental health. These reasons are different from those reported by Mannion et al. ${ }^{12}$ in a study of 88 patients in which the majority expected much improvement in leg pain (63\%) and walking capacity (67\%). Our initial hypothesis was that patients with depressive symptoms would expect less from their surgery, but this hypothesis was not confirmed by our results. The impact of expectations on outcomes remains unclear, with some authors decrying their use as a valid measure of the overall quality or effectiveness of surgical spine care because it represents a patient's subjective contentment with health care services. ${ }^{7,15}$

Satisfaction concerning leg pain, walking improvement, and independence was lower in the group with persistent depression symptoms. Generally, satisfaction was also lower in patients with persistent depression symptoms; only 5 patients (33\%) in this group selected the option "surgery helped a lot," as compared with 33 patients (76\%) in the normal mood group. Similarly, Adogwa et al. ${ }^{3}$ described a cohort of 53 patients who had undergone revision surgery for symptomatic same-level recurrent stenosis. Depression was measured using the Zung self-rating depression scale. Significant improvement from 37.52 to 49.9 ( $\mathrm{p}<0.001$ ) was noted in the scale, and the authors concluded that an increased preoperative Zung depression score was associated with patient dissatisfaction 2 years after revision lumbar surgery.

When measuring the clinical outcomes of surgical treatment for spinal stenosis, certain individual patient characteristics should be considered. In our study, the depression symptoms prior to and after surgery led to worse clinical outcomes and different patient expectations and expectations fulfilled. This finding emphasizes the importance of the routine assessment of patient mood and expectations. These factors can then be discussed with patients to achieve realistic and oriented outcomes of surgery.

\section{Conclusions}

Surgery for spinal stenosis has a relieving effect on preoperative depression symptoms at the 1-year followup. The persistence of depressive symptoms after surgery correlates with worse clinical outcomes and a higher rate of unmet expectations. Screening measures to detect and treat depression symptoms in the perioperative period could improve clinical results and patient satisfaction.

\section{References}

1. Aalto TJ, Malmivaara A, Kovacs F, Herno A, Alen M, Salmi $\mathrm{L}$, et al: Preoperative predictors for postoperative clinical outcome in lumbar spinal stenosis: systematic review. Spine (Phila Pa 1976) 31:E648-E663, 2006

2. Abbott AD, Tyni-Lenné R, Hedlund R: Leg pain and psychological variables predict outcome 2-3 years after lumbar fusion surgery. Eur Spine J 20:1626-1634, 2011

3. Adogwa O, Parker SL, Shau DN, Mendenhall SK, Bydon A, Cheng JS, et al: Preoperative Zung depression scale predicts patient satisfaction independent of the extent of improvement after revision lumbar surgery. Spine J 13:501-506, 2013

4. Beck AT, Ward CH, Mendelson M, Mock J, Erbaugh J: An inventory for measuring depression. Arch Gen Psychiatry 4:561-571,1961

5. Daltroy LH, Cats-Baril WL, Katz JN, Fossel AH, Liang MH: The North American Spine Society lumbar Spine Outcome Assessment Instrument: reliability and validity tests. Spine (Phila Pa 1976) 21:741-749, 1996

6. Fairbank JC, Pynsent PB: The Oswestry Disability Index. Spine (Phila Pa 1976) 25:2940-2952, 2000

7. Godil SS, Parker SL, Zuckerman SL, Mendenhall SK, Devin CJ, Asher AL, et al: Determining the quality and effectiveness of surgical spine care: patient satisfaction is not a valid proxy. Spine J 13:1006-1012, 2013

8. Katz JN, Stucki G, Lipson SJ, Fossel AH, Grobler LJ, Weinstein JN: Predictors of surgical outcome in degenerative lumbar spinal stenosis. Spine (Phila Pa 1976) 24:2229-2233, 1999

9. Lattig F, Fekete TF, O'Riordan D, Kleinstück FS, Jeszenszky $\mathrm{D}$, Porchet F, et al: A comparison of patient and surgeon preoperative expectations of spinal surgery. Spine (Phila Pa 1976) [epub ahead of print], 2012

10. Licina P, Johnston M, Ewing L, Pearcy M: Patient expectations, outcomes and satisfaction: related, relevant or redundant? Evid Based Spine Care J 3:13-19, 2012

11. Lutz GK, Butzlaff ME, Atlas SJ, Keller RB, Singer DE, Deyo RA: The relation between expectations and outcomes in surgery for sciatica. J Gen Intern Med 14:740-744, 1999

12. Mannion AF, Junge A, Elfering A, Dvorak J, Porchet F, Grob D: Great expectations: really the novel predictor of outcome 
after spinal surgery? Spine (Phila Pa 1976) 34:1590-1599, 2009

13. Mariconda M, Zanforlino G, Celestino GA, Brancaleone S, Fava R, Milano C: Factors influencing the outcome of degenerative lumbar spinal stenosis. J Spinal Disord 13:131-137, 2000

14. McGregor AH, Doré CJ, Morris TP: An exploration of patients' expectation of and satisfaction with surgical outcome. Eur Spine J 22:2836-2844, 2013

15. McGregor AH, Hughes SPF: The evaluation of the surgical management of nerve root compression in patients with low back pain: Part 2: patient expectations and satisfaction. Spine (Phila Pa 1976) 27:1471-1477, 2002

16. Menendez M, Neuhaus V, Bot A, Ring D, Cha TD: Psychiatric disorders and major spine surgery: epidemiology and perioperative outcomes. Spine (Phila Pa 1976) 39:E111E122, 2014

17. Sinikallio S, Aalto T, Airaksinen O, Herno A, Kröger H, Savolainen S, et al: Depression and associated factors in patients with lumbar spinal stenosis. Disabil Rehabil 28:415422, 2006

18. Sinikallio S, Aalto T, Airaksinen O, Herno A, Kröger H, Viinamäki H: Depressive burden in the preoperative and early recovery phase predicts poorer surgery outcome among lumbar spinal stenosis patients: a one-year prospective follow-up study. Spine (Phila Pa 1976) 34:2573-2578, 2009

19. Sinikallio S, Aalto T, Airaksinen O, Lehto SM, Kröger H, Viinamäki H: Depression is associated with a poorer outcome of lumbar spinal stenosis surgery: a two-year prospective follow-up study. Spine (Phila Pa 1976) 36:677-682, 2011

20. Skolasky RL, Riley LH III, Maggard AM, Wegener ST: The relationship between pain and depressive symptoms after lumbar spine surgery. Pain 153:2092-2096, 2012

21. Soroceanu A, Ching A, Abdu W, McGuire K: Relationship between preoperative expectations, satisfaction, and functional outcomes in patients undergoing lumbar and cervical spine surgery: a multicenter study. Spine (Phila Pa 1976) 37:E103-E108, 2012
22. Sriwatanakul K, Kelvie W, Lasagna L, Calimlim JF, Weis OF, Mehta G: Studies with different types of visual analog scales for measurement of pain. Clin Pharmacol Ther 34:234-239, 1983

23. Tharin S, Mayer E, Krishnaney A: Lumbar microdiscectomy and lumbar decompression improve functional outcomes and depression scores. Evid Based Spine Care J 3:65-66, 2012

24. Toyone T, Tanaka T, Kato D, Kaneyama R, Otsuka M: Patients' expectations and satisfaction in lumbar spine surgery. Spine (Phila Pa 1976) 30:2689-2694, 2005

25. Wahlman M, Häkkinen A, Dekker J, Marttinen I, Vihtonen K, Neva M: The prevalence of depressive symptoms before and after surgery and its association with disability in patients undergoing lumbar spinal fusion. Eur Spine J 23:129_ 134,2014

\section{Author Contributions}

Conception and design: Zárate-Kalfópulos, Romero-Vargas. Acquisition of data: Zárate-Kalfópulos, Urban-Baeza, BrenesRojas. Analysis and interpretation of data: Zárate-Kalfópulos, Urban-Baeza, Romero-Vargas, Obil-Chavarría. Drafting the article: Zárate-Kalfópulos. Critically revising the article: ZárateKalfópulos, Romero-Vargas, Brenes-Rojas. Reviewed submitted version of manuscript: Zárate-Kalfópulos, Urban-Baeza, Romero-Vargas, Obil-Chavarría, Reyes-Sánchez. Approved the final version of the manuscript on behalf of all authors: Zárate-Kalfópulos. Statistical analysis: Zárate-Kalfópulos. Administrative/technical/material support: Zárate-Kalfópulos, Reyes-Sánchez. Study supervision: Zárate-Kalfópulos, ReyesSánchez.

\section{Correspondence}

Barón Zárate-Kalfópulos, Instituto Nacional de Rehabilitación, Spine Surgery Service, Calzada México-Xochimilco 289, Col. Arenal de Guadalupe, Tlalpan, 14389 México Distrito Federal, México.email: baronzk@hotmail.com. 